\title{
Bentuk Penyajian dan Nilai Filosofi Tari Muwang Sangkal Sumenep Untuk Anak Kelas VI Di sekolah Dasar
}

\author{
Muhammad Misbahudholam AR ${ }^{1)}$, Framz Hardiansyah ${ }^{2)}$, Sama ${ }^{\text {3) }}$ \\ ${ }^{123}$ Prodi Pendidikan Guru Sekolah Dasar, STKIP PGRI Sumenep
}

* Corresponding Author. E-mail: $\underline{1}$ misbahudholam@stkippgrisumenep.ac.id

\begin{tabular}{|l|l|l|}
\hline Receive: 03/01/2021 & Accepted: 20/02/2021 & Published: 01/03/2021
\end{tabular}

\begin{abstract}
Abstrak
Filosofi dan nilai Tari Muwang Sumenep dikaji dalam penelitian ini untuk siswa Kelas VI SDN Pandian V Sumenep. pada studi ini, siswa Kelas VI SDN Pandian V Sumenep akan belajar tentang Filosofi Tari Muwang Sangkal Sumenep. Ini menggunakan metode deskriptif yang berfokus pada menggambarkan apa yang dijelaskan. Wawancara terstruktur observasional dan pendekatan dokumentasi diambil untuk mengumpulkan data untuk penelitian ini. Menurut temuan, kelas tari diadakan dua kali seminggu di SDN Pandian V Sumenep. Bagi siswa SDN Pandian V Sumenep diadakan kelas tari untuk mengasah dan mengembangkan bakatnya. Selain itu, mereka dapat melihat bagaimana filosofi itu disajikan dan betapa pentingnya secara keseluruhan. Untuk menampilkan tari Muwang Sangkal, anak-anak hanya perlu mempelajari urutan gerakannya. Sementara itu, anak-anak dapat mempelajari secara detail dan jelas tentang nilai filosofi tari Muwang Sangkal, seperti syarat seorang penari Muwang Sangkal dalam keadaan suci dan tidak sedang haid, dan harus memiliki sifat rendah hati dan tidak sombong. Untuk siswa sekolah dasar, teori tari Muwang Sangkal sama dengan teori tari Muwang Sangkal pada umumnya. Riasan dan fashion hanyalah dua dari banyak perbedaan antara pria dan wanita. Hingga saat ini tari Muwang Sangkal Sumenep telah diakui sebagai lambang Kabupaten Sumenep oleh masyarakat Sumenep dan menjadi kebanggaan tersendiri bagi masyarakat Sumenep.
\end{abstract}

Kata Kunci: Bentuk Penyajian, Nilai Filosofi, Tari Muwang Sangkal Sumenep

The Form of Presentation and Value of the Philosophy of Muwang Sangkal Sumenep Dance for Class VI Children in Elementary School

\begin{abstract}
The philosophy and values of the Muwang Sumenep Dance were studied in this study for the sixth-grade students of SDN Pandian V Sumenep. In this study, Grade VI students of SDN Pandian V Sumenep will learn about the Dance Philosophy of Muwang Sangkal Sumenep. It uses a descriptive method that focuses on describing what is described. Observational structured interviews and documentation approaches were taken to collect data for this study. According to the findings, dance classes are held twice a week at SDN Pandian V Sumenep. For students of SDN Pandian V Sumenep, dance classes are held to hone and develop their talents. In addition, they can see how the philosophy is presented and how important it is overall. To perform the Muwang Sangkal dance, children only need to learn the sequence of movements. Meanwhile, children can learn in detail and clearly about the philosophical values of Muwang Sangkal dance, such as the requirements for a Muwang Sangkal dancer to be pure and not menstruating and to be humble and not arrogant. For elementary school students, Muwang Sangkal dance theory is the same as Muwang Sangkal dance theory in general. Makeup and fashion are just two of the many differences between men and women. The Sumenep Muwang Sangkal dance has been recognized as a symbol of the Sumenep Regency by the Sumenep community and has become a source of pride for the Sumenep people.
\end{abstract}

Keywords: Forms of Presentation, Philosophical Values, Muwang Sangkal Sumenep Dance 


\section{Pendahuluan}

Faktor eksternal (keluarga, sekolah, dan masyarakat) secara signifikan mempengaruhi perkembangan bakat, minat, dan kemampuan anak, begitu juga dengan faktor internal (gen anak) (Istianah, 2021). Untuk membantu siswa mencapai potensi penuh mereka, lembaga pendidikan berupaya menciptakan lingkungan yang memfasilitasi pertumbuhan ini (Atika, Wakhuyudin, \& Fajriyah, 2019). Sebagai bagian dari upaya yang lebih signifikan untuk meningkatkan kesejahteraan manusia, pendidikan untuk anak-anak sangat penting (Rijal \& Bachtiar, 2015). Ketika bertindak sebagai pendidik, wajar saja jika guru ingin memberikan informasi sebanyak mungkin kepada siswanya. Seorang guru akan melakukan segala yang dia bisa untuk memastikan bahwa setiap pengetahuan yang diberikan kepada siswa dimanfaatkan dengan baik, tentu saja dengan cara yang paling sederhana, yaitu dengan memaksimalkan waktu yang dihabiskan di kelas (Nurhasanah \& Sobandi, 2016).

Guru diharapkan memiliki otoritas mengajar karena pelatihan dan pengalaman mereka sebagai guru. Guru harus memiliki keahlian khusus dalam pendidikan jika ingin memenuhi tanggung jawabnya sebagai pendidik (Andriani \& Rasto, 2019). Mengembangkan potensi peserta didik agar menjadi manusia yang beriman dan bertakwa kepada Tuhan Yang Maha Esa, berakhlak mulia, sehat dan berilmu, cakap, kreatif dan mandiri, serta menjadi demokratis (Mursalim, 2019). Warga negara yang bertanggung jawab dapat terbantu dalam pembangunan pendidikan nasional sesuai dengan kebutuhan masyarakat dan bangsa Indonesia yang sedang mengembangkan tujuan pendidikan nasional.

Akibatnya, diharapkan kehidupan pribadi siswa akan meningkat karena pendidikan (Sadikin \& Hamidah, 2020). (Handarini \& Wulandari, 2020), mengajar di bidang seni dan budaya dapat membantu siswa menemukan bakat dan minat unik mereka di luar kelas. Karena budaya adalah konsep multifaset yang mencakup kemampuan dan kebiasaan siswa sebagai anggota masyarakat dan pengetahuan, kepercayaan, seni, moral, ilmu pengetahuan, dan hukum, maka penting bagi siswa untuk belajar tentang budaya, terutama budaya daerah mereka sendiri. Penting untuk diingat bahwa anak-anak masih manusia dengan banyak potensi yang belum dimanfaatkan (Karmadi, 2007).

Mereka memiliki karakteristik unik yang berbeda dan berbeda dari orang dewasa; mereka selalu dinamis, antusias, dan ingin tahu tentang dunia di sekitar mereka (Zainal, 2014). Tidak seperti orang dewasa, anak-anak memiliki rentang perhatian yang pendek dan potensi belajar yang paling signifikan. Mereka juga senang bergerak, dan gerakannya cukup beragam, antara lain berjalan, melompat, berjingkrak, dan sebagainya (Sauri, 2011). Mengajar siswa tentang budaya tari di daerah mereka dan menekankan betapa pentingnya mencintai budaya sendiri dapat menjadi cara yang sangat baik bagi pendidik atau guru untuk memanfaatkan ini (Brata Ida Bagus, 2016). Di Sumenep, tari Muwang Sangkal merupakan salah satu contoh budaya lokal yang berkembang menjadi simbol Kabupaten Sumenep hingga saat ini. Tari Muwang Sangkal yang sudah dikenal masyarakat Sumenep akan disuguhkan kepada siswa SD dan tenaga pendidik di SDN Pandian V Sumenep.

Mereka sebelumnya telah berusaha untuk mengajarkan budaya Sumenep, termasuk Tari Muwang Sangkal. Untuk membangkitkan minat siswa pada budaya mereka sendiri dan memungkinkan guru untuk mengembangkan potensi mereka dan menghargai perasaan yang mereka alami. Salah satu fungsi sistem budaya adalah mengatur dan menentukan tindakan dan perilaku siswa melalui adat dan norma. Unsur-unsur tersebut dibentuk agar perilaku manusia termanifestasi dalam unsur-unsur 
budaya secara utuh, sehingga tercipta satu kesatuan yang kohesif (Siregar, 2017).

Interaksi antara manusia dan segala sesuatu yang ada di alam semesta menyebabkan munculnya budaya (Sadikin \& Hamidah, 2020). Kita sebagai pendidik diperbolehkan untuk membantu siswa kita menyadari potensi penuh mereka karena mereka dilahirkan dengan semua potensi yang sudah ada di dalam diri mereka, yang kemudian dapat kita gunakan untuk membantu mereka tumbuh. Karena dilahirkan ke dunia sebagai makhluk yang berbudaya, seharusnya mereka diajarkan tentang budayanya sendiri sejak dini untuk membantu membentuk budaya di daerahnya (Handarini \& Wulandari, 2020).

Sebagai hasil dari penciptaan mereka, mereka juga bergantung secara budaya; budaya penduduk setempat sebagian besar membentuk budaya mereka (Cahyani, Listiana, \& Larasati, 2020). Sebagai contoh tari Muwang Sangkal Sumenep yang telah diuraikan di atas mengalami perkembangan yang pesat dan kini telah dikenal masyarakat baik di dalam maupun di luar kota Sumenep. Kebudayaan yang diciptakan manusia berimplikasi pada daerah tempat ia tumbuh. Siswa di SDN Pandian V Sekolah Sumenep dapat menggunakan seni tari dan musik untuk mengekspresikan bakat mereka, dan hal ini telah terjadi sejak diperkenalkannya bentuk tari Muwang Sangkal di Sumenep. Tradisi Muwang Sangkal di Istana Sumenep adalah menabur nasi kuning sebagai tanda penghormatan dan penyambutan tamu yang berkunjung ke istana. Beberapa orang bergotong royong menabur padi kuning yang disinyalir memiliki kekuatan untuk menangkal malapetaka. Tari Muwang Sangkal Sumenep yang awalnya hanya dipentaskan di Keraton, telah menjadi sumber kebanggaan dan kekuatan yang signifikan bagi masyarakat.

Belakangan ini diketahui bahwa masyarakat umum memiliki pemahaman yang salah tentang tari Muwang sangkal, baik dari segi koreografi dan tujuannya maupun persyaratan ketat lainnya, seperti jumlah penari dan pakaiannya. Orang asing bisa melihat ciri khas suatu budaya dari luar. Selain itu, kita sebagai pendidik harus memiliki pemahaman yang lebih mendalam tentang budaya Indonesia untuk mendidik anak didik kita, seiring dengan semakin banyaknya budaya asing yang masuk ke tanah air (Cahyono, 2019). Artinya budaya yang diterapkan dan dikembangkan di daerah tertentu berdampak pada pola perilaku, norma, dan nilai yang akan menjadi ciri khas masyarakat dengan masyarakat lainnya (Naim, 2012).

\section{Metode}

SDN Pandian V Sumenep dipilih sebagai lokasi penelitian peneliti. Peneliti memilih sekolah ini karena menawarkan kegiatan ekstrakurikuler tari sehingga memudahkan peneliti untuk melakukan penelitian dan mengidentifikasi solusi dari permasalahan yang ada. Pendekatan yang dilakukan dalam penelitian ini adalah kualitatif, artinya penelitian yang diilhami postpositivisme digunakan untuk mengkaji kondisi objek-objek alam.

Peneliti menggunakan pendekatan kualitatif untuk mendeskripsikan bagaimana filosofi tari Muwang Sangkal Sumenep disajikan kepada siswa kelas VI SDN Pandian V Sumenep. Peneliti berharap dengan melakukan penelitian ini, mereka akan menjawab beberapa masalah yang diangkat selama kerja lapangan dan melalui wawancara mendalam dengan informan. Desain penelitian kualitatif deskriptif penelitian ini berasal dari istilah mendeskripsikan yang berarti menggambarkan atau menggambarkan sesuatu, seperti keadaan, kondisi, situasi, peristiwa, atau kegiatan. Jadi, penelitian deskriptif mengkaji tentang keadaan, keadaan suatu hal, yang hasilnya disajikan dalam suatu penelitian.

Prosedur Pengumpulan Data Langkah paling kritis dalam penelitian adalah pengumpulan data, karena tujuan utama penelitian adalah untuk mendapatkan data. Tanpa memahami teknik pengumpulan data, peneliti tidak akan dapat 
memperoleh data yang sesuai dengan standar data yang telah ditetapkan. Peneliti menggunakan dua teknik pengumpulan data yang berbeda: Observasi, Wawancara. Teknik pengumpulan data ini didasarkan pada laporan diri sendiri atau setidaknya berdasarkan pengetahuan dan keyakinan pribadi. Dokumentasi adalah catatan peristiwa masa lalu. Dokumen dapat berbentuk tulisan, gambar, atau karya monumental oleh seorang individu. Saat meneliti penelitian ini, peneliti memperoleh dokumentasi berupa foto atau gambar. Gaya penyajian dan pentingnya falsafah Muwang Sangkal bagi siswa kelas VI SDN Pandian V Sumenep.

\section{Hasil dan Pembahasan}

\section{A. Gaya Penyajian Tari Muwang Sangkal}

Kegiatan Tari diadakan dua kali seminggu di Sekolah SDN Pandian V Sumenep, pada hari Rabu dan Minggu pukul 15:00 WIB. Kegiatan menari memungkinkan anak-anak mengasah bakat dan mengembangkan potensi yang ada pada diri mereka (wawancara dengan Pak Edi Susanto, 09 Agustus 2020). Menurut pernyataan dari SDN Pandian V Sumenep, siswa kelas enam, "mereka telah mengikuti kegiatan menari sejak kelas I; mereka diperbolehkan untuk belajar, mengekspresikan diri, dan mengembangkan potensi mereka tanpa takut akan paksaan. Dari kepala sekolah atau guru." Banyak manfaat yang mereka peroleh dari mengikuti kegiatan tari, salah satunya tari Muwang Sangkal Sumenep di sekolah, antara lain dapat lebih mengenal tari, menghibur diri, tampil di luar kota seperti di Surabaya dan Malang, hingga berkompetisi di tingkat kabupaten dan provinsi, serta meni

mba pengalaman. Selain itu, dengan mengikuti kegiatan tari, khususnya tari Muwang Sangkal, mereka dapat memahami gaya penyajian dan nilai filosofi yang terkait dengan tari Muwang Sangkal secara keseluruhan. Misalnya dalam tari Muwang Sangkal penarinya harus perempuan dan dalam keadaan suci atau tidak sedang haid dan manusia. Harus memiliki perilaku yang sederhana, kerendahan hati yang terusmenerus, dan ketakwaan yang tak tergoyahkan kepada Tuhan Yang Maha Esa (wawancara dengan Norma Isatin, 02 Agustus 2020).

Anak-anak lebih ditekankan memahami gerakan dan urutannya melalui penyajian tari Muwang Sangkal Sumenep khusus untuk anak kelas VI SD di SDN Pandian V Sumenep, berbeda dengan anak dewasa yang bisa melakukan gerakan dan menikmati masing-masing dengan rasa (wawancara dengan Pak Edi Susanto, 09 Agustus 2020).

Menurut Bapak Agus Widodo, seniman tari Kabupaten Sumenep, tari Muwang Sangkal Sumenep disajikan dengan cara yang sesuai dengan asal usul tari, yaitu dari tradisi atau kebiasaan keluarga besar Keraton Sumenep. Jika dipadukan dengan kostum yang dikenakan para penari Muwang Sangkal, khususnya gaun pengantin asli Sumenep yaitu cahaya, cahaya tersebut mengembangkan kepribadian tari Muwang Sangkal dan menambah keindahannya.

Gerakan tari Muwang Sangkal Pak Agus Widodo sendiri menyatakan bahwa ia sangat dipengaruhi oleh gerakan tari Jawa lainnya, karena Sumenep, Madura, dan Jawa saling terkait. Namun hal tersebut tidak meniadakan keberadaan tari Muwang Sangkal yang ditunjang dengan penarinya yang mengenakan pakaian adat pernikahan Sumenep dan tabur Beras kuning yang berasal dari adat istiadat keluarga Keraton zaman dahulu kala kedatangannya. tamutamu hebat juga diterima dan diakui oleh semua orang. Menurut masyarakat Sumenep, tari Muwang Sangkal merupakan ciri khas Sumenep (wawancara 17 Agustus 2020). Tarian Muwang Sangkal Sumenep terdiri dari unsur-unsur sebagai berikut:

a. Gerak adalah berirama yang dihasilkan oleh tubuh manusia dari ujung kepala sampai ujung kaki. Gerakan tari Muwang Sangkal Sumenep mengingatkan pada kehidupan sehari- 
hari di Keraton Sumenep yang dicirikan oleh kesantunan, kharisma, dan kelembutan putri-putri Keraton Sumenep.

b. Musik Musik merupakan unsur yang sulit dipisahkan dari tari, terbukti dari pernyataan siswa kelas VI SDN Pandian V Sumenep bahwa ketika berlatih tari Muwang Sangkal tanpa iringan musik, mereka kurang semangat bahkan mungkin lupa geraknya.

c. Konsep tata rias dalam tari Muwang Sangkal berbeda dengan anak-anak dewasa. Di sekolah dasar, riasan anakanak natural, cantik, dan tidak terlalu kecil, sehingga tetap mempertahankan keanggunannya dan terlihat seperti anak-anak. Anak-anak dewasa sudah memakai rias pengantin.

Tarian Muwang Sangkal ini didandani dengan busana pengantin Sumenep yaitu ringan yang diterjemahkan sebagai "bahu telanjang". Perbedaan pakaian anak SD dan orang dewasa saat menampilkan tari Muwang Sangkal adalah pada ukuran; Pakaian anak sekolah dasar panjangnya 3 meter, sedangkan pakaian orang dewasa panjangnya 5-6 meter. Selain itu, pakaian dalam tari Muwang Sangkal menampilkan dua warna berbeda yang mewakili kebesaran dan kekuatan Keraton Sumenep: merah dan kuning, yang menunjukkan bahwa orang Sumenep memiliki jiwa pemberani, mudah dinasihati, dan ramah, sedangkan hijau dan kuning. menunjukkan bahwa orang Sumenep memiliki sopan santun dan tidak pernah kalah.

Cirinya, Siswa kelas VI SDN Pandian V Sumenep menggunakan mangkok kuningan dan Nasi kuning untuk menampilkan tari Muwang Sangkal. Penari Muwang Sangkal menggunakan mangkok kuningan karena kuningan sangat tahan lama dan semakin indah bila digosok dengan air buah asam; mangkok kuningan juga berfungsi sebagai wadah Nasi Kuning yang dibawa oleh masing-masing penari.
Beras Kuning merupakan simbol tari Muwang Sangkal yang melambangkan kesuburan, dan warna kuning melambangkan kejayaan masyarakat Sumenep. Beras Kuning digunakan untuk mengatasi kesulitan dan menandai akhir dari pertunjukan tari Muwang Sangkal. Secara historis, tari Muwang Sangkal hanya bisa dipentaskan atau ditampilkan di Istana Sumenep.

Namun seiring berjalannya waktu dan perkembangan zaman, tarian ini mulai dipentaskan di ruang terbuka, tergantung kebutuhan pementasannya. Seperti gedung, balai, dan lapangan, seperti pada tahun 2016, tarian ini dibawakan sebagai bagian dari upacara pembukaan HUT ke-747 kota Sumenep di depan Masjid Raya Sumenep dengan kurang lebih 125 penari wanita. Sehingga seluruh lapisan masyarakat di Kabupaten Sumenep dapat dengan nyaman menyaksikan tari Muwang Sangkal.

Lantai Pola lantai yang digunakan siswa kelas VI SDN Padian V Sumenep saat menampilkan tari Muwang Sangkal identik dengan pola lantai orang dewasa. Lantai dansa Muwang Sangkal Sumenep dirancang untuk mengakomodasi berbagai gerakan yang dijelaskan di atas.

Jumlah penari Tarian Muwang Sangkal Sumenep harus aneh. Orang Sumenep pada zaman dahulu lebih menyukai bilangan ganjil, karena berkaitan dengan jumlah shalat wajib bagi umat Islam, jumlah shalat witir, dan rukun Islam. Akibatnya, tari Muwang Sangkal harus bernomor ganjil.

\section{B. Nilai Filosofis Tari Muwang Sangkal Sumenep}

Makna filosofis tari Muwang Sangkal Sumenep dapat diartikan sebagai pedoman atau standar yang melandasi keberadaan tari Muwang Sangkal saat ini. Nilai filosofis juga dapat menggambarkan budaya atau cara hidup masyarakat Sumenep kuno. Sebagaimana dijelaskan oleh Bapak Taufiqqurrahman, koreografer tari Muwang Sangkal Sumenep pada tahun 1972, nilai filosofis tari Muwang Sangkal terdiri dari tiga poin: 1 . Nilai permohonan 
kepada Tuhan Yang Maha Esa, 2. Nilai kesucian, dan 3. Nilai kerendahan hati dan tidak sombong (wawancara 02 April 2020).

Tari Muwang Sangkal berawal dari sebuah ritual atau tradisi untuk menyapa para pejabat di Istana Sumenep. Awalnya hanya ditemukan di Keraton Sumenep pada saat upacara penyambutan, tradisi ini ditinggalkan dan muncul kembali pada tahun 1972 dalam bentuk tarian ciptaan Pak Taufiqqurrahman (wawancara dengan Pak Edi Susanto, 09 Agustus 2020). Tari Muwang Sangkal dihadirkan untuk menyambut para pejabat di Istana Sumenep. Makna filosofis tari Muwang Sangkal adalah permohonan kepada Yang Maha Kuasa untuk menjaga mereka tetap aman. Tari Muwang Sangkal dibawakan oleh musik tradisional Madura khususnya gamelan yang dipimpin oleh Pak Rifai.

Busana yang dikenakan dalam Tari Muwang Sangkal adalah busana adat Keraton Sumenep yang dikenal dengan Godot light. Tarian Muwang Sangkal mewujudkan kepercayaan masyarakat Sumenep bahwa menggunakan Beras kuning pada acara-acara seperti upacara pernikahan, pelantikan, dan tamu kehormatan Keraton Sumenep, adalah ritual sial. Eksistensi Tari Muwang Sangkal, khususnya bagi masyarakat Sumenep, sangat penting karena tarian ini berkembang menjadi kekuatan masyarakat, karena pada awalnya ditampilkan secara eksklusif di Keraton Sumenep. Namun seiring berjalannya waktu, Tari Muang Sangkal telah dibawakan di luar lingkungan Keraton Sumenep, sehingga Tari Muwang Sangkal dapat disaksikan oleh seluruh masyarakat Sumenep.

Tari Muwang Sangkal dalam masyarakat Sumenep tidak hanya mengacu pada nilai estetikanya saja tetapi juga fungsinya sebagai alat ritual yang berisi permohonan dan doa kepada yang maha kuasa untuk menghindari bencana. Dalam hal ini, masyarakat Sumenep percaya bahwa tari Muwang Sangkal adalah sakral. Berikut ini diuraikan nilai-nilai filosofi yang terkandung dalam tari Muwang Sangkal Sumenep secara lebih rinci:

1. Pentingnya doa kepada Yang Maha Esa Manusia berdoa kepada yang maha kuasa untuk perlindungan dari marabahaya dengan hati yang murni. Hubungan manusia dengan yang ilahi terkait erat. Sebagai hamba Allah, manusia wajib menunaikan kewajiban dan menjauhi segala larangan Allah SWT.

Menurut Bapak Edi Susanto (wawancara, 09 Agustus 2020), nilai permohonan tari Muwang Sangkal kepada yang maha kuasa dapat dilihat pada gerakan terakhir yaitu penaburan Beras Kuning. Beras melambangkan kesuburan Keraton Sumenep, sedangkan warna kuning pada Beras melambangkan keagungan keraton. Sumenep. Dengan demikian, Beras Kuning digunakan sebagai simbol memohon kepada penari untuk menghindari bahaya, dengan kepala penari tidak menghadap ke depan tetapi setengah tertunduk menghormati Yang Maha Kuasa dan tubuh penari condong ke depan.

2. Makna kesucian Nilai kesucian artinya ketika manusia mendekati yang maha kuasa harus dalam keadaan suci yang artinya harus bersih dan bebas dari najis pada seluruh anggota tubuh. Karena hubungan antara manusia dengan Tuhannya disebut ibadah, dan ibadah menunjukkan bahwa seorang hamba menaati Tuhannya dan menegakkan keberadaan Tuhan.

Sistem nilai tari Muwang Sangkal Sumenep dapat ditarik dari aturan penari. Menurut Pak Taufiqurrahman, koreografer tari Muwang Sangkal Sumenep (wawancara 02 April 2020), dan Pak Edi Susanto, guru tari di SDN Pandian V Sumenep (wawancara 09 Agustus 2020), tari Muwang menyangkal bahwa penari harus dalam keadaan suci atau tidak sedang haid dan masih perempuan.

Tarian Muwang Sangkal mirip dengan doa manusia dalam hal semuanya harus dalam keadaan suci, yang berarti bahwa anak tidak boleh menstruasi atau 
menstruasi, yang berarti keluarnya darah dari dinding rahim penari yang telah mencapai pubertas, untuk mempertahankan kemurnian tari Muwang Sangkal. Diperlukan konsentrasi yang tinggi saat melakukan tari Muwang Sangkal, sebagai melakukan ibadah atau ritual sebagai sarana mendekatkan diri kepada Yang Maha Kuasa, serta saat menari tari Muwang Sangkal, yang membutuhkan konsentrasi tinggi agar gerak dan emosi menyatu dengan mulus, memungkinkan penonton untuk menikmati setiap alunan gerakannya.

3. Pentingnya menjaga sikap rendah hati dan menghindari kesombongan

Menjadi rendah hati dan sederhana adalah kualitas yang harus dimiliki setiap manusia. Pentingnya bersikap rendah hati dan tidak sombong terlihat dalam komunikasi dan perilaku mereka dengan manusia lain. Manusia pada dasarnya tidak sombong; mereka benarbenar ikhlas dan sungguh-sungguh bekerja untuk Tuhan, tidak peduli seberapa banyak pujian yang mereka terima dari orang lain karena semua yang mereka miliki dan semua yang ada di bumi ini adalah milik yang maha kuasa, yang secara berkala kembali kepada-Nya.

Menurut Bapak Edi Susanto (wawancara, 09 Agustus 2020), tari Muwang Sangkal mewujudkan nilai rendah hati dan tidak sombong dari awal sampai akhir, tepatnya posisi kepala yang tidak terlalu maju atau setengah membungkuk. ; dari posisi ini, terlihat jelas bahwa masyarakat Sumenep selalu tenang dan tidak sombong. Hal ini juga terlihat pada gerakan Tompang Tale Panjang Kanan dan Kiri, dimana tangan penari digerakkan ke atas dan ke bawah seperti seutas tali, menunjukkan bahwa mereka selalu rendah hati, dan pada posisi berjalan penari saat menari dengan anggun atau meliuk-liuk indah di antara keduanya. gerakan masingmasing, yang melambangkan jiwa mereka yang lembut dan tidak sombong.

\section{Simpulan}

Siswa di Sekolah SDN Pandian V Sumenep dapat mengembangkan bakat dan potensi mereka dengan mengikuti kegiatan menari dua kali seminggu, pada hari Rabu dan Minggu pukul 15.00 WIB setiap minggunya. Tari Muwang Sangkal, sebuah bentuk tarian lokal, diperkenalkan kepada mereka sebagai contoh dari apa yang bisa mereka lakukan. Secara umum, teori tari Muwang Sangkal untuk siswa sekolah dasar sama dengan untuk orang dewasa; Namun, kemampuan anak-anak untuk memproses rasa masih lebih lemah daripada orang dewasa, sehingga mereka tidak dapat memproses setiap gerakan seefektif orang dewasa. Dalam tari muwang sangkal, setiap posisi badan dan kepala direndahkan setengah. Gerakannya yang anggun melambangkan kesopanan dan bukan keangkuhan para putri keraton. Tarian tradisional Kabupaten Sumenep, tari Muwang Sangkal Sumenep, telah menjadi simbol nasional. Tari Muwang Sangkal Keraton Sumenep memiliki nilai dan makna yang sama dengan kehidupan sehari-hari. Generasi muda khususnya di Kabupaten Sumenep dapat menjaga dan melestarikan kesenian Sumenep khususnya tari Muwang Sangkal dengan segala nilai-nilainya. Untuk menjaga agar tari Muwang Sangkal tetap lestari untuk generasi mendatang, diharapkan kita dapat terus belajar lebih banyak tentang tari dan menemukan solusi inovatif untuk masalah. Masyarakat di Kabupaten Sumenep peduli dengan seni dan ingin melakukan bagian mereka untuk melestarikannya untuk generasi mendatang. Hal ini juga mendorong anak-anak untuk mengejar passion dan minat mereka di luar sekolah, seperti berpartisipasi dalam kegiatan seni karena mereka adalah duta generasi penerus warisan budaya Sumenep.

\section{Daftar Pustaka}

Andriani, R., \& Rasto, R. (2019). Motivasi belajar sebagai determinan hasil belajar siswa. Jurnal Pendidikan Manajemen Perkantoran, 4(1), 80. 
https://doi.org/10.17509/jpm.v4i1.149 58

Atika, N. T., Wakhuyudin, H., \& Fajriyah, K. (2019). Pelaksanaan Penguatan Pendidikan Karakter Membentuk Karakter Cinta Tanah Air. Mimbar Ilmu, 24(1), 105. https://doi.org/10.23887/mi.v24i1.174 67

Brata Ida Bagus. (2016). Kearifan BudayaLokal Perekat Identitas Bangsa. Jurnal Bakti Saraswati. Diakses Pada Hari Minggu 20 Juli 2019. Pukul 00.00 WIB, 05(01), 9-16. https://doi.org/10.1007/s11104-0089614-4

Cahyani, A., Listiana, I. D., \& Larasati, S. P. D. (2020). Motivasi Belajar Siswa SMA pada Pembelajaran Daring di Masa Pandemi Covid-19. IQ (Ilmu AlQur'an): Jurnal Pendidikan Islam, 3(01), 123-140. https://doi.org/10.37542/iq.v3i01.57

Cahyono, H. (2019). Faktor-Faktor Kesulitan Belajar Siswa Min Janti. Jurnal Dimensi Pendidikan Dan Pembelajaran, $\quad 7(1), \quad 1$. https://doi.org/10.24269/dpp.v7i1.163 6

Handarini, O. I., \& Wulandari, S. S. (2020). Pembelajaran Daring Sebagai Upaya Study From Home (SFH). Jurnal Pendidikan Administrasi Perkantoran (JPAP), 8(3), 465-503.

Istianah, A. (2021). Implementasi Metode Among Untuk Meningkatkan Karakter. Jurnal Kalacakra: Ilmu Sosial Dan Pendidikan, 2(1), 34. https://doi.org/10.31002/kalacakra.v2i 1.3534

Karmadi, A. (2007). Budaya Lokal Sebagai Warisan Budaya dan Upaya Pelestariannya. Dialog Budaya Daerah Jawa Tengah, 1-6. Retrieved from

http://kebudayaan.kemdikbud.go.id/wp content/uploads/sites/37/2014/11/Buda ya_Lokal.pdf

Mursalim.

(2019).

Membangun
Interkoneksi antara Pendidikan Formal, Non-Formal, dan Informal. (August 2008), 1-10. Retrieved from https://www.researchgate.net/publicati on/334884207_15-

Membangun_Interkoneksi_antara_Pen didikan Formal Non-

Formal dan Informal

Naim, N. (2012). Mengembalikan Misi Pendidikan Sosial Dan Kebudayaan Pesantren. Jurnal Pendidikan Islam UIN Sunan Gunung Djati, 27(3), 449462.

Nurhasanah, S., \& Sobandi, A. (2016). Minat Belajar Sebagai Determinan Hasil Belajar Siswa. Jurnal Pendidikan Manajemen Perkantoran, 1(1), 128. https://doi.org/10.17509/jpm.v1i1.326 4

Rijal, S., \& Bachtiar, S. (2015). Hubungan antara Sikap, Kemandirian Belajar, dan Gaya Belajar dengan Hasil Belajar Kognitif Siswa. Jurnal Bioedukatika, 3(2),

15. https://doi.org/10.26555/bioedukatika. v3i2.4149

Sadikin, A., \& Hamidah, A. (2020). Pembelajaran Daring di Tengah Wabah Covid-19. Biodik, 6(2), 109119.

https://doi.org/10.22437/bio.v6i2.9759

Sauri, S. (2011). Membangun Komunikasi dalam Keluarga (Kajian Religi, Sosial, dan Edukatif). Bandung: Grapindo.

Siregar, N. R. (2017). Persepsi siswa pada pelajaran matematika: studi pendahuluan pada siswa yang menyenangi game. Prosiding Temu Ilmiah $X$ Ikatan Psikologi Perkembangan Indonesia, 224-232.

Zainal, A. (2014). Penelitian Tindakan: Metode dan Paradigma Baru (Remaja Ros). Bandung: Remaja Rosdakarya. Retrieved from https://scholar.google.com/scholar?hl= id\&as_sdt $=0 \% 2 \mathrm{C} 5 \& \mathrm{q}=$ Zainal + Arifin. $+2014 .+$ Penelitian+Pendidikan+Metod $\mathrm{e}+$ Dan+Paradigma + Baru. + Bandung $\%$ $3 \mathrm{~A}+\mathrm{PT}+$ Remaja + Rosda + Karya.\&btnG 


\section{Profil Penulis 1}

Muhammad Misbahudholam AR, M.Pd, lahir di Sumenep, Jawa Timur, pada Tanggal 20 April 1989. Menempuh pendidikan pada Sekolah Dasar Kambingan Barat dan lulus pada tahun 2000, melanjutkan pendidikan pada SMP Negeri I Lenteng dan lulus pada tahun 2003, kemudian melajutkan pendidikan pada MAN I Sumenep dan lulus pada tahun 2006., melajutkan pendidikan Sarjana (S1) pada Jurusan Geografi Fakultas IImu Sosial Universitas Negeri Malang dan lulus pada tahun 2010, kemudian melanjutkan pendidikan Magister (S2) pada Jurusan Pendidikan Geografi Universitas Negeri Malang. Dan lulus pada tahun 2012. la adalah anak pertama dari 2 bersaudara, sekarang mengabdi sebagai Dosen disalah satu perguruan tinggi di Pulau Madura tepatnya Prodi Pendidikan Guru Sekolah Dasar STKIP PGRI Sumenep.

\section{Profil Penulis 2}

Framz Hardiansyah, dilahirkan pada tanggal 07 Juli 1992 di Kabupaten Sumenep, ujung timur pulau Madura sebagai putra pertama dari pasangan Drs. Masturi, M. Pd dan Ratna Juniwati, S. Pd, serta istri Erfi Megasari, S.sos. Pendidikan penulis di tempuh Sekolah Dasar di SDN Pangarangan $V$ Sumenep lulus pada tahun 2004. Pendidikan berikutnya di SMPN 1 Sumenep lulus pada tahun 2007. Selanjutnya menempuh pendidikan pada SMAN 1 Sumenep lulus pada tahun 2010.
Setelah lulus dari SMA penulis berkesempatan melanjutkan pendidikan ke Perguruan Tinggi di Universitas PGRI Adibuana Surabaya dengan Program Studi Pendidikan Pancasila dan Kewarganegaraan, lulus pada tahun 2014 dengan menjadi mahasiswa terbaik di Universitas. Terakhir melanjutkan Pascasarjana di Universitas Negeri Surabaya dengan Program Studi Pendidikan Dasar, lulus pada tahun 2017. sekarang mengabdi sebagai Dosen disalah satu perguruan tinggi STKIP PGRI Sumenep di Pulau Madura tepatnya Prodi Pendidikan Guru Sekolah Dasar STKIP PGRI Sumenep.

\section{Profil Penulis 3}

Sama', S.Pd, M.Pd., lahir di Sumenep pada tanggal 3 September 1986. Dari Ibu bernama Murta dan Ayah bernama $\mathrm{H}$. Wasil. la memiliki seorang istri bernama Faridatul Quraini, S.Pd. Penulis bertempat tinggal di Desa Kalianget Barat Kecamatan Kalianget Kabupaten Sumenep. Telah menyelesaikan studi stara satu di Program Pendidikan Sekolah Dasar STKIP PGRI Sumenep (2010-2014). Lulus stara dua di Pendidikan Dasar Universitas Negeri Surabaya (2014-2016). sekarang mengabdi sebagai Dosen disalah satu perguruan tinggi STKIP PGRI Sumenep di Pulau Madura tepatnya Prodi Pendidikan Guru Sekolah Dasar STKIP PGRI Sumenep. 